\title{
Strength and Ductility with Dual Grain-Size and Texture Gradients in AZ31 Mg Alloy
}

\author{
JIAWEI YAN, JIAWEI MA, JIAN WANG, and YAO SHEN \\ Using surface rotation rolling (SRR) treatment with various vertical loads (120 to $280 \mathrm{~N}$ ) while \\ maintaining other processing parameters (rotation speed and horizontal velocity), the \\ SRR-treated AZ31 Mg alloy sheets exhibit through-thickness gradients of both grain size and \\ basal texture, as revealed by cross-sectional hardness tests and microstructure analysis. An \\ optimal strength-ductility combination is achieved as the vertical load is around $200 \mathrm{~N}$. The \\ corresponding microstructure exhibits two characters: (1) The affected depth reaches the very \\ center of the sheet and (2) the gradients approach the allowable maximum. Texture gradient is \\ found to be the major contributor to the significant ductility enhancement.
}

https://doi.org/10.1007/s11661-018-4874-y

(c) The Minerals, Metals \& Materials Society and ASM International 2018

\section{INTRODUCTION}

Magnesium (Mg) alloy, the lightest among structural materials, is an attractive material for reducing vehicle weight thus increasing the efficiency in terms of fuel consumption and reducing the emission of greenhouse gas. ${ }^{[1,2]}$ However, their applications have been limited due to their low strength and poor deformability. ${ }^{[1]}$ According to the fundamental principle of tailoring the relative activities of basal slips, non-basal slips, and twins, several approaches to improving the deformability and strength of $\mathrm{Mg}$ alloys have been proposed, such as increasing processing temperature, ${ }^{[3,4]}$ alloying with appropriate solutes ${ }^{[5-8]}$ refining grain sizes, ${ }^{[9-11]}$ weakening textures, ${ }^{[12-14]}$ and forming metallic laminates. ${ }^{[15-17]}$

Refining grain sizes of magnesium alloys can be accomplished by severe plastic deformation (SPD) processes, such as equal channel angular pressing $(\mathrm{ECAP})^{[10,18]}$ and high-pressure torsion (HPT). ${ }^{[19,20]}$ Refining grain sizes in the surface layer has been demonstrated to enhance mechanical properties of the bulk materials, and corresponding techniques are easy to scale up. For instance, surface mechanical attrition treatment (SMAT) can refine grains in the surface layer of different materials ${ }^{[21-24]}$ and develop the grain-size gradient from the surface. Corresponding to the gradient of grain size, the incompatibility of plastic deformation

JIAWEI YAN, JIAWEI MA, and YAO SHEN are with the State Key Lab of Metal Matrix Composites, School of Materials Science and Engineering, Shanghai Jiao Tong University, Shanghai 200240, China. Contact e-mail: yaoshen@sjtu.edu.cn JIAN WANG is with the Department of Mechanical and Materials Engineering, University of Nebraska-Lincoln, Lincoln, NE 68588.

Manuscript submitted March 14, 2018.

Article published online August 22, 2018 will develop in different depths, and results in an extra strain hardening and a long-range back stress. Compared with homogeneous grain refining, ${ }^{[22,24]}$ refining grain sizes in the surface layer could result in a superior ductility-strength combination of surface-treated materials. In addition to refining grain sizes with a gradient, texture can also influence the tensile strength and ductility because of the strong plasticity anisotropy in Mg alloys. ${ }^{[13]}$ Recently, Chen et al. ${ }^{[25]}$ has found that, in addition to refining grain sizes, SMAT can also modify textures with a gradient distribution along depth. Such texture gradient significantly improves the ductility-strength combination compared with the grain-size gradient, e.g., in steel, ${ }^{[22,26]}$ aluminum ${ }^{[27]}$ and magnesium alloys without strong basal textures. ${ }^{[28]}$

In our experiment, we modified grain size and texture in the surface layer of AZ31 sheets on both sides by surface rotation rolling (SRR) technique. Compared with SMAT $[25,29]$ and other similar surface treatments, ${ }^{[2,30,31]}$ SRR treatment can be utilized for large plates and result in fine surface finishing. By changing vertical loads, we tailored the microstructure with gradients in grain size and basal texture contents, and conducted tensile testing of SRR-treated samples. An optimal strength-ductility combination is achieved as the vertical load is around $200 \mathrm{~N}$. The roles of the grain-size gradient and the texture gradient are discussed in terms of their influences on strength and ductility. Texture gradient is found to be the major contributor to the significantly enhanced ductility.

\section{EXPERIMENT}

A commercial hot-rolled AZ31 alloy sheet with an average grain size of about $20 \mu \mathrm{m}$ was used in this study. 
The SRR device is set up in a computer numeric control (CNC) turret machine tool, as shown in Figure 1. It includes a vacuum chuck, a working head, and a vertical spindle. The working head, which consists of three parallel springs and a planar bearing with cemented carbide balls (3 $\mathrm{mm}$ in diameter), is installed on the vertical spindle. The AZ31 sheet is held tightly on the vacuum chuck and rolled by ten cemented carbide balls confined inside a rotating working head that is pressed with a vertical load $\mathrm{P}$ along the normal direction (TD) of the sheet. During the SRR processing, the working head rotates with a rotation speed of $\omega=540 \mathrm{rpm}$ and then moves back and forth with the horizontal speed of $v=100 \mathrm{~mm} / \mathrm{min}$ along the rolling direction (RD) of the sheet. The vertical load was controlled at constant values of $120,160,200,240$, and $280 \mathrm{~N}$, respectively, in order to optimize the microstructures of AZ31 sheet in terms of texture and grain size. Sufficient cooling liquid with lubrication was used to suppress heating and surface damages. The initial $1.00-\mathrm{mm}$-thick plate was deformed to 0.87 to $0.92 \mathrm{~mm}$, depending on the vertical load.

Tensile specimens with a gauge dimension of $15 \mathrm{~mm} \times 5 \mathrm{~mm}$ were machined parallel to the rolling direction of the sheet. For each SRR-treated sample, we prepared two tensile specimens. Tensile tests were carried out using a Zwick testing machine at a strain rate of $1 \times 10^{-3} \mathrm{~s}^{-1}$ at room temperature. All the cross sections mentioned in this study are perpendicular to the

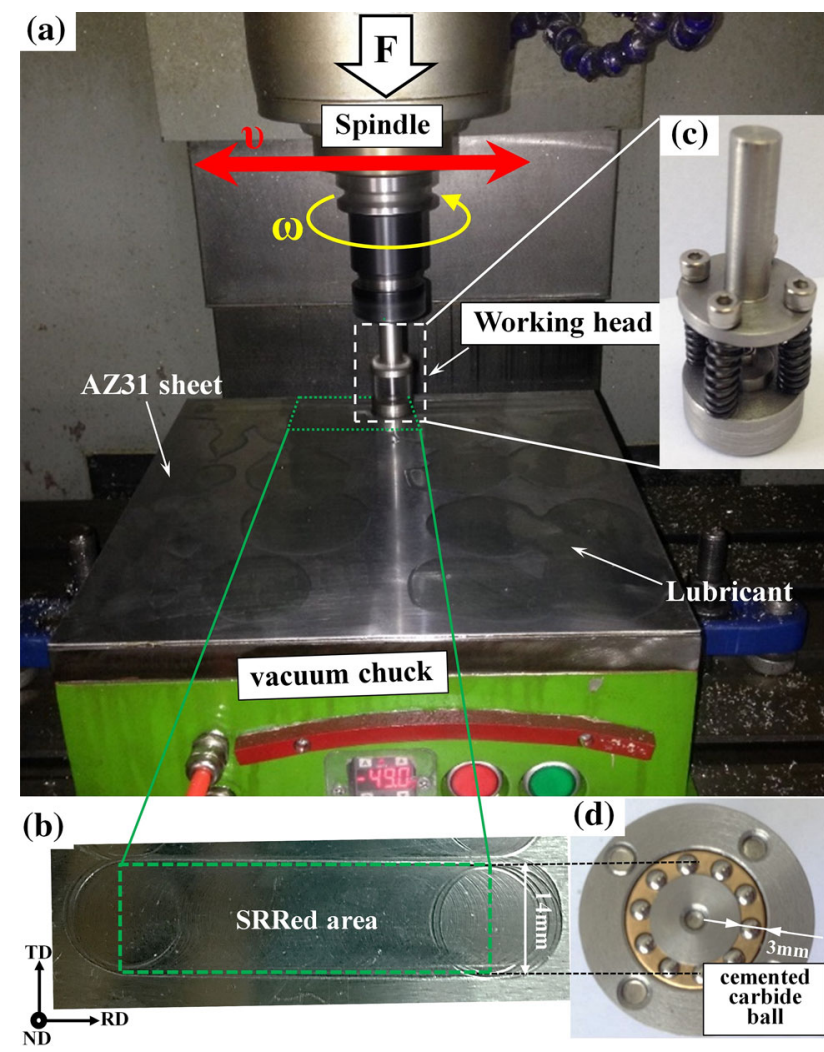

Fig. 1-(a) The device for surface rotation rolling treatment. (b) The AZ31 sheet sample treated by SRR. (c) The enlarged normal view, and $(d)$ bottom view of the working head. transversal direction (TD) of the sample. The cross-sectional microhardness of the SRR-treated samples was measured using a Buehler 402SXV Microhardness Tester with a load of $10 \mathrm{~g}$ and a dwell time of 10 seconds. At least five indents were conducted for each depth from the surface. Cross-sectional microstructure was characterized using a scanning electron microscope (SEM) with an electron backscatter diffraction (EBSD) detector, with the step sizes varying from 0.2 to $2 \mu \mathrm{m}$. HKL Channel 5.0 software was used to analyze and process the EBSD data. EBSD samples were prepared by electrochemical polishing using perchloric acid solution ( $25 \mathrm{~mL}$ perchloric acid $+475 \mathrm{~mL}$ ethanol) at $-20{ }^{\circ} \mathrm{C}$ and applying $17 \mathrm{~V}$ for about 7 minutes. Cross-sectional microstructure in the surface layer was also characterized by transmission electron microscope (TEM, JEOL 2100) at the operating voltage of $200 \mathrm{kV}$. TEM samples were prepared by gluing two cross-sectional thin foils in a face-to-face manner and then inserting it into a copper ring for thinning by $\mathrm{Ar}$ ion milling.

\section{RESULTS}

The SRR-treated AZ31 sheets show an increase in strength with a little sacrifice of ductility, as shown in Figure 2(a). The yield strength $\left(\sigma_{\mathrm{YS}}\right)$ of the SRR-treated samples is about twice that of the as-received sample $(\sim 250$ vs $137 \mathrm{MPa})$. The ultimate tensile strength $\left(\sigma_{\text {UTS }}\right)$ also increases from 226 to $308 \mathrm{MPa}$. The elongation to failure $(\varepsilon)$ remains the same as the as-received sample when the vertical load $P$ is 200 or $240 \mathrm{~N}$. The optimal combination of strength $\left(\sigma_{\mathrm{YS}}=208 \mathrm{MPa}\right.$, $\left.\sigma_{\mathrm{UTS}}=294 \mathrm{MPa}\right)$ and ductility $(\varepsilon=21.5 \mathrm{pct})$ is obtained at $P=200 \mathrm{~N}$. The $\sigma_{\mathrm{UTS}}$ and $\varepsilon$ values of both the as-received and the SRR-treated samples are summarized in the inset of Figure 2(a), which shows a hump feature at $P=160 \mathrm{~N}, 200$, and $240 \mathrm{~N}$ that deviates from the conventional linear strength-ductility variation in either uniform or gradient grain-size materials. [22,26,28,31-34] $^{2}$

To understand the hump feature in Figure 2(a), we further characterized the variation of the cross-sectional hardness, the depth of the hardened layer, and the microstructures along the depth for different vertical loads. The cross-sectional hardness of SRR-treated samples exhibits a gradient variation, as plotted in Figure 2(b) as a function of the depth from the surface, according to which, we determined the depth of the hardened layer. The depth of the hardened layer increases with the increasing $P$, and is increased throughout the whole sample when $P$ exceeds $200 \mathrm{~N}$. The cross-sectional hardness increases with the vertical load. The hardness in the near surface increases to 112 $\mathrm{HV}$ compared with $65 \mathrm{HV}$ in the as-received material when $P=120 \mathrm{~N}$, and finally reaches a peak value of $130 \mathrm{HV}$ when $P$ exceeds $200 \mathrm{~N}$. With further increasing of $P$, up to $280 \mathrm{~N}$, the hardness at different depths continuously increases except at the top surface, where the hardness reaches a peak of $130 \mathrm{HV}$ and the saturation depth increases up to $60 \mu \mathrm{m}$. The larger 


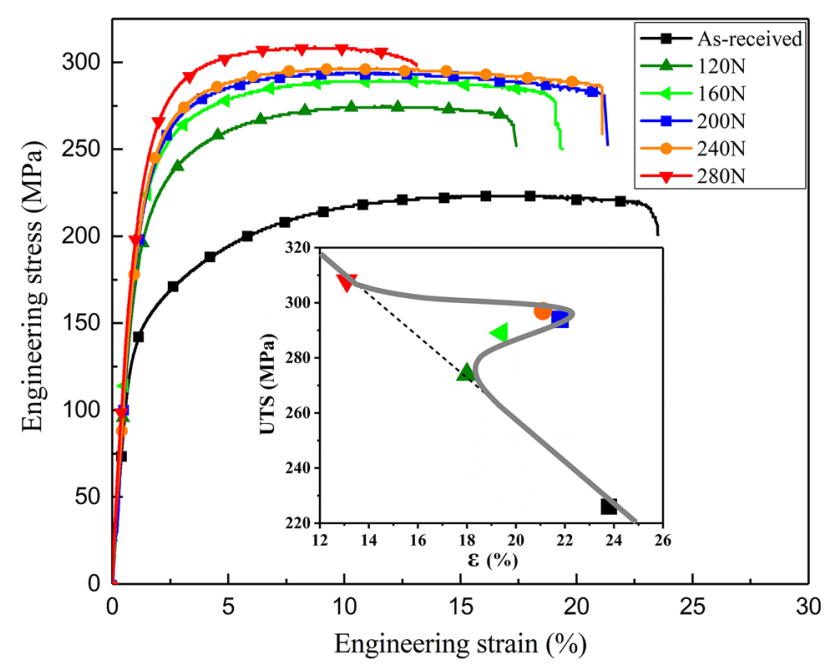

(a)

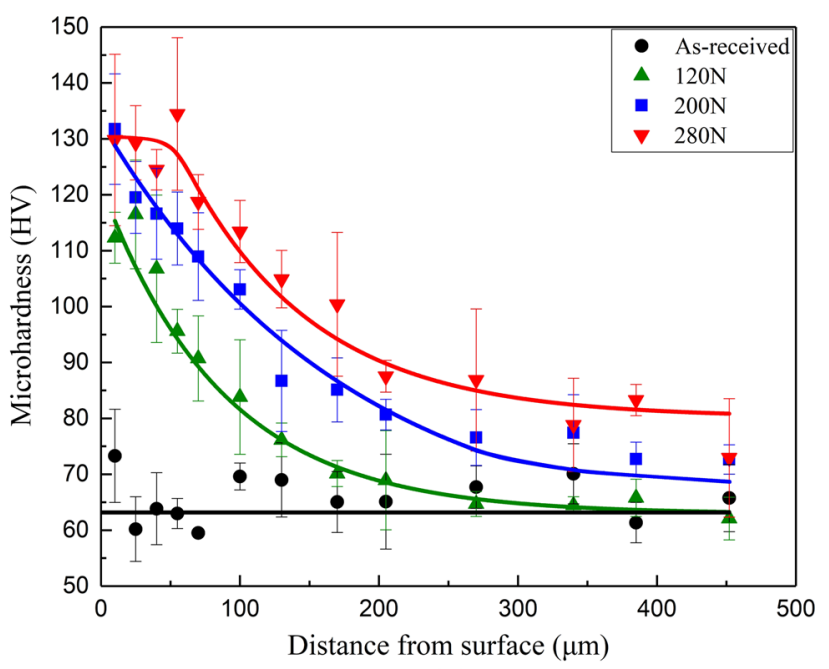

(b)

Fig. 2-(a) The uniaxial tensile tests and (b) curves of microhardness along depth, for the as-received and the surface rotation rolling-treated AZ31 samples.

scatters and fluctuation in the mean value of hardness within the top surface layer are presumed to indicate the occurrence of over hardening that induces flaws and hardness reduction.

The grain size exhibits a gradient distribution along the depth from surface after SRR treatment, and particularly, the highly refined grains within the top layer are transversally equiaxed, as shown in Figure 3 (microstructural characterizations with a larger range along depth can be found in Figure 4). The refined region is about $60 \mu \mathrm{m}$ deep when $P=120 \mathrm{~N}$, and at least $150 \mu \mathrm{m}$ deep when $P=280 \mathrm{~N}$. The cross-sectional microstructure at the depth of $10 \mu \mathrm{m}$ was characterized with TEM as shown in Figure 3(i). The continuous rings in the corresponding selected area electron diffraction (SAED) patterns (the inset) indicate that the orientations of these nanocrystals are nearly randomly distributed. The transversal grain-size distribution of the layer about $10 \mu \mathrm{m}$ beneath the surface is presented in Figure 4(j) with an average size of 117 nm, a typical size that can be achieved in surface mechanical treatment of AZ31 sheet with various techniques, such as SMAT, ${ }^{[25,29]}$ sliding friction treatment, ${ }^{[31]}$ and wire-brushing. [23]

As the depth of grain-refined layer is much smaller than that of the hardened layer (the latter reaches almost to the most center when $P \geq 200 \mathrm{~N}$ ), it is needed to reach beneath the grain-refined layer and check the other microstructural aspects such as degree of deformation and texture variations. The degrees of deformation are characterized by the band contrast figures and the "recrystallized fraction" illustrations in Figure 4. The band contrast figures can reveal some slip bands, e.g., those at the central area of $280 \mathrm{~N}$ sample. The "recrystallized fraction" function in HKL Channel 5 software identifies each grain as "severely deformed," "substructured," (with subgrains) or "recrystallized" (nearly undeformed in the current study), depending on the average internal misorientation within each individual grain or subgrain. The sequence of these three types of grains from the surface down to the central area is in accordance with the decrease of plastic deformation along depth. The deformed depth includes that of both "severely deformed" and "substructured" grains, which is nearly the same as that of the hardened layer for each sample, as listed in Table I. These findings explain why the depth of grain-refined layer is much smaller than that of the hardened layer: either small or large plastic deformation can result in hardening but only the large can refine grains.

Accompanying with grain-size gradient, texture also exhibits gradient along the depth, i.e. the content of basal texture is gradually weakened from the center area outward to the surface layer, as shown in Figure 4. Weakening basal texture, evidenced by the expansion of (0001) orientation cluster, occurs until the maximum depth of $200 \mu \mathrm{m}$ when $P=120 \mathrm{~N}$, and it extends to the center of the sample when $P$ increases to $200 \mathrm{~N}$. The basal texture is further weakened along the depth with $P=280 \mathrm{~N}$. Weakening of basal textures at different loads is also quantified and compared as shown in Figure 4(d). The reduction of basal texture contents in SRR-treated samples is calculated as the relative reduction compared with the as-received sample, where the basal texture contents are the summation of intensity of (0001) orientations that are within a critical degree around ND. Error bars in Figure 4(d) indicate the variations in measurement when the critical angle varies within the range of 8 to $12 \mathrm{deg}$. It is noted that for each sample, the depth of texture-weakened layer is nearly the same as that of hardened layer or deformed layer, as listed in Table I.

\section{DISCUSSION}

By virtue of the through-thickness dual gradients, the best strength-ductility combination of AZ31 sheets was obtained using SRR technique with $P=200 \mathrm{~N}$, as shown in Figure 5, compared to its counterparts by various deformation processes, including homogeneous refinement and SMAT. ${ }^{[23,25,29,31,35-37]}$ It is noted that the 


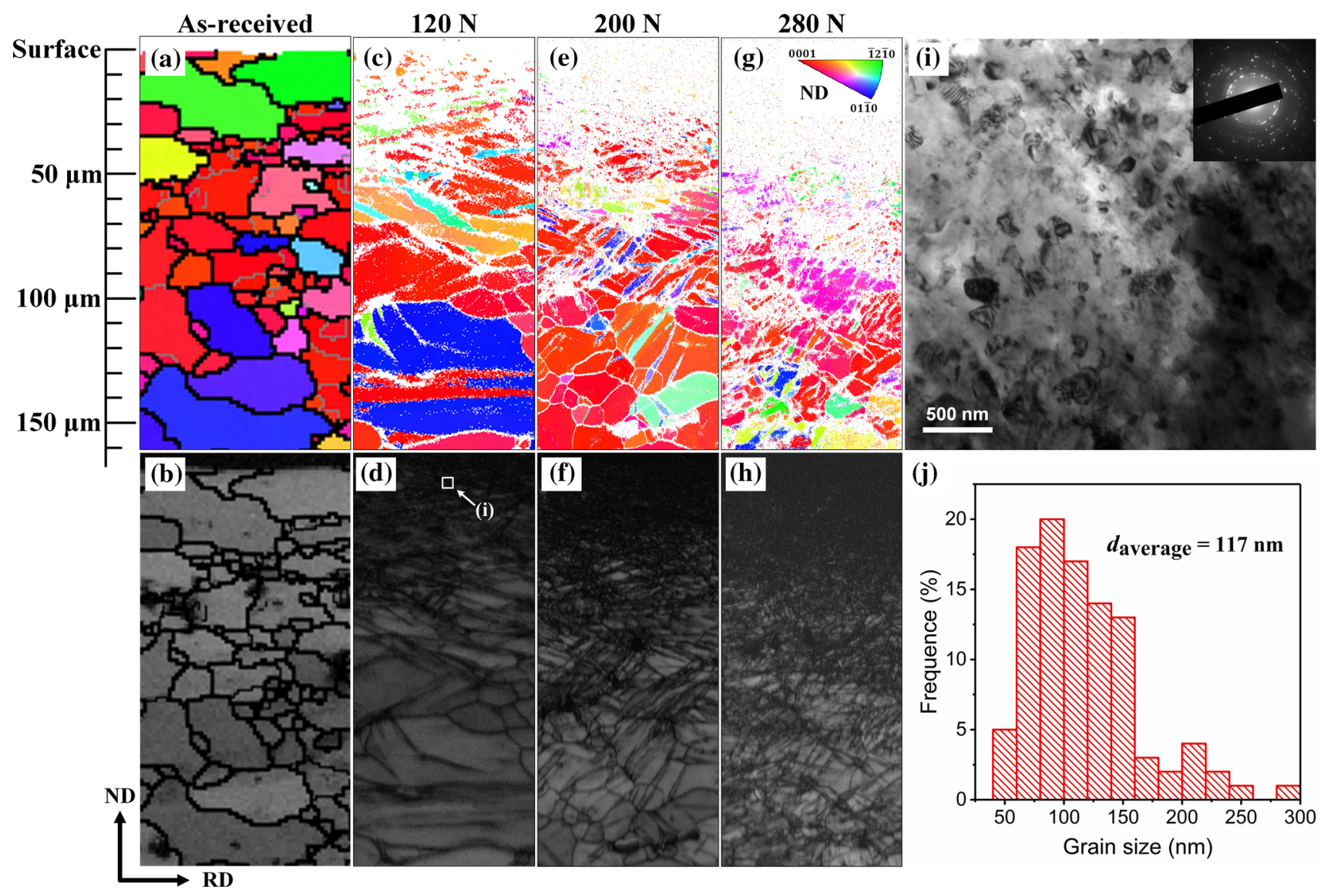

Fig. 3-Inverse pole figures (IPF) and corresponding band contrast figures of $(a),(b)$ the as-received AZ31 sample, and the samples treated by surface rotation rolling with loads of $(c),(d) 120 \mathrm{~N},(e),(f) 200 \mathrm{~N}$, and $(g),(h) 280 \mathrm{~N}$. (i) A cross-sectional bright field TEM image of the microstructures about $10 \mu \mathrm{m}$ beneath the surface of the $120 \mathrm{~N}$ sample, as enclosed by the white square in (d). The inset shows the selected area electron diffraction pattern. ( $j$ ) The distribution and the average value of the transversal grain size obtained from the cross-sectional TEM measurements.

SRR-treated sample with the optimal mechanical performance exhibits the dual gradients in the whole sample (about $0.9 \mathrm{~mm}$ ) but no over hardening, compared to the case when $P=280 \mathrm{~N}$.

The tensile strength increases monotonically with the vertical load $P$. This is attributed to the increase in the hardness and the thickness of the hardened layer. However, the ductility exhibits an abnormal fluctuating trend. At $P=120 \mathrm{~N}$, grain refinement and hardening happen within a limited depth on the surface, and the degree of texture weakening is similarly limited. Therefore, in terms of back stress, the positive effects of grain-size and texture gradients on hardening and ductility are limited. Correspondingly, the ductility follows the usual "stronger-less ductile" trend. This is consistent with the results of those SMAT materials with no obvious (or enough) texture gradient, which exhibit the monotonous decrease in ductility with monotonous increase of strength. ${ }^{[28,34,38]}$ At the optimal load of $200 \mathrm{~N}$, the gradients in hardness/ strength expand to the whole thickness and result in the spreading of back stress in the whole volume. Accompanied with grain-size gradient from the surface $\sim 150 \mu \mathrm{m}$ layer, the gradient weakening of basal textures gives extra contribution to back stress because it can create gradients in plastic strains, which, in turn, generates back stress.
This auxiliary effect originates from the large plastic anisotropy in hexagonal metals. In addition to back stress hardening, weakened basal texture itself is proposed to improve ductility by facilitating more basal/non-basal slips and/or activating tensile twinning, ${ }^{[12,14]}$ although comprehensive mechanisms are lacking. At $P=280 \mathrm{~N}$, ductility decreases again after the hardening had already reached the very center. This can be explained by the fact that all gradients including hardness, grain size, and basal texture have decreased in terms of the degree. Meanwhile, the grain refinement on the surface reaches the maximum and dislocations stored in the grains of the middle area increase extensively. As a consequence, such over hardening leads to lack of further strain hardening during deformation as well as the reduction of ductility. An additional reason is that surface damage is likely to occur upon over hardening.

Thus, it could be inferred that gradient, in terms of textures, is more important than grain-size gradient and defect gradients, including dislocation and deformation twinning, for the improvement in ductility. This is supported by three arguments. First, the depth of texture gradient is much larger than that of grain-size gradient and twinning gradient, but it is in coincidence with the depth of hardness gradients that controls the 


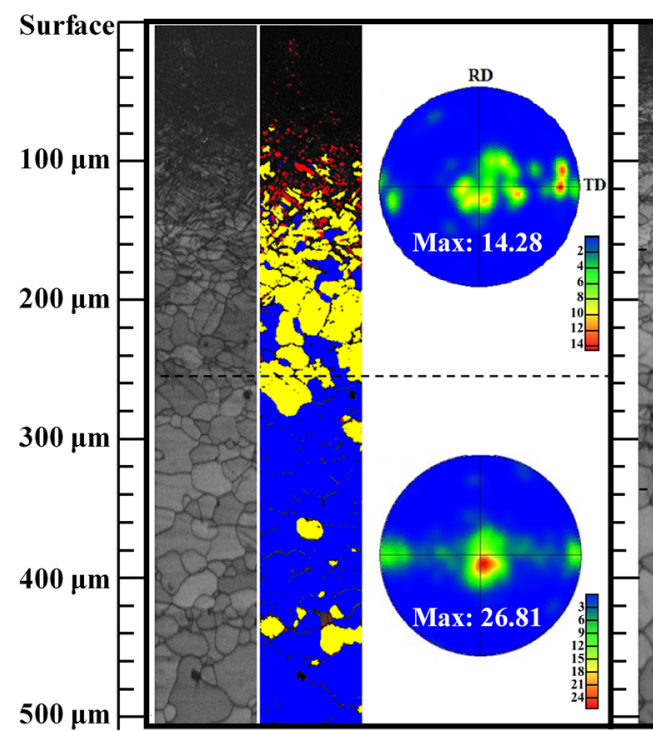

(a) $120 \mathrm{~N}$

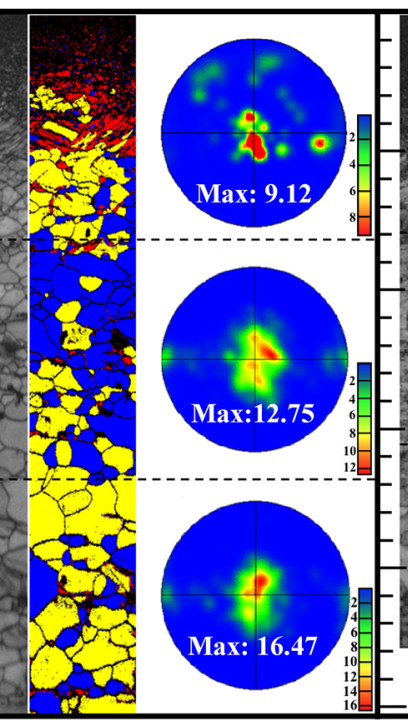

(b) $200 \mathrm{~N}$

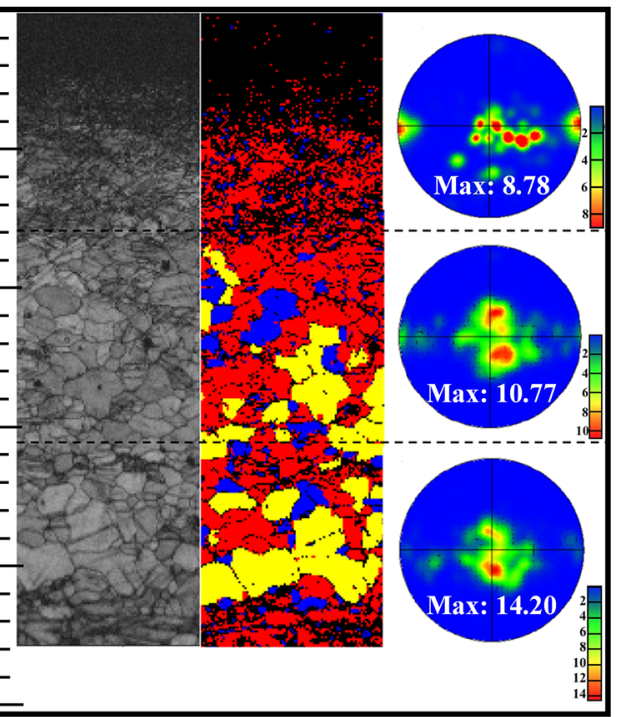

(c) $280 \mathrm{~N}$

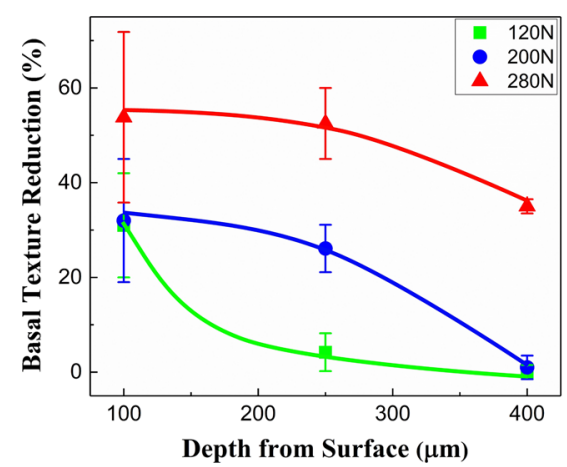

(d)

Fig. 4-Band contrast figures, recrystallized fraction illustrations (fully recrystallized grains are shown in blue, substructured grains in yellow, and severely deformed grains in red), and (0001) pole figures from different depths of AZ31 samples with loads of $(a) 120 \mathrm{~N},(b) 200 \mathrm{~N}$, and $(c)$ 280 N. All pole figures are plotted with RD in North and TD in East directions. (d) The variations of reduction in basal texture contents along depth at the three loads (Color figure online).

Table I. The Thickness and Volume Fractions of Hardened/Grain-Refined/Deformed/Texture-Weakened Layers with Different Loads

\begin{tabular}{lcccc}
\hline$P(\mathrm{~N})$ & $T_{\mathrm{HL}}(\mu \mathrm{m})$ & $T_{\mathrm{GL}}(\mu \mathrm{m})$ & $T_{\mathrm{DL}}(\mu \mathrm{m})$ & $T_{\mathrm{WL}}(\mu \mathrm{m})$ \\
\hline 120 & $250(44.4 \mathrm{pct})$ & $60(13.3 \mathrm{pct})$ & $260(57.8 \mathrm{pct})$ & $240(53.3 \mathrm{pct})$ \\
200 & $450(100 \mathrm{pct})$ & $120(26.7 \mathrm{pct})$ & $450(100 \mathrm{pct})$ & $450(100 \mathrm{pct})$ \\
280 & $450(100 \mathrm{pct})$ & $160(35.6 \mathrm{pct})$ & $450(100 \mathrm{pct})$ & $450(100 \mathrm{pct})$ \\
\hline
\end{tabular}

\footnotetext{
layer.

back stress distribution. Second, the gradient of weakening basal texture in hcp crystals contributes much more than the back stress generated by grain-size gradient, as mentioned above, because of the strong anisotropy of plastic deformation. Third, one system, with mainly grain-size gradient and dislocation-density variations across the thickness but with a little amount of texture gradients, usually exhibits monotonic "harder-less ductile" trend. ${ }^{[28,34,38]}$
}

The percentages shown in parentheses are the volume fractions of different layers in the whole sample thickness (around $0.9 \mathrm{~mm}$ ).

$T_{\mathrm{HL}}$, thickness of hardened layer; $T_{\mathrm{GL}}$, thickness of grain-refined layer; $T_{\mathrm{DL}}$, thickness of deformed layer; $T_{\mathrm{WL}}$, thickness of texture-weakened

\section{CONCLUSION}

In summary, the surface rotation rolling method is applied to produce AZ31 Mg alloy sheet with dual gradients in terms of grain size and weakened basal textures. This is promising for large-scale applications in metal plate forming or processing. The optimal strength-ductility happens when the volume exhibiting gradient in strength reaches the maximum allowable 


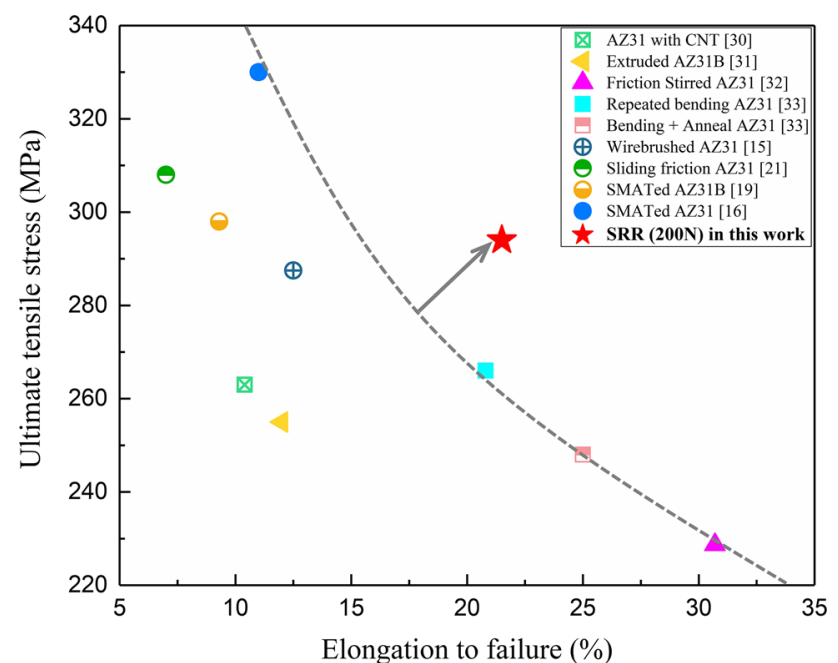

Fig. 5-Comparison of mechanical performance between the current study and other references. The data point of this study is for the $200 \mathrm{~N}$ sample.

limit without over hardening to reduce the gradient in the surface or the center. It is suggested that the texture gradient is more important in improving ductility than the grain-size gradient, especially for hexagonal closepacked structures exhibiting significant plastic anisotropy.

\section{ACKNOWLEDGMENTS}

This study is supported by the National Key Research and Development Plan (Grant No. 2016YFB0701201), the National Science Foundation of China (Nos. 51471107 and 51671132), and the Materials Genome Initiative Center, Shanghai Jiao Tong University.

\section{REFERENCES}

1. B.L. Mordike and T. Ebert: Mater. Sci. Eng. A, 2001, vol. 302, pp. $37-45$.

2. H. Friedrich and S. Schumann: J. Mater. Process. Technol., 2001, vol. 117 , pp. $276-81$.

3. H. Watanabe and M. Fukusumi: Mater. Sci. Eng. A, 2008, vol. 477 , pp. $153-61$.

4. H. Fan, Q. Wang, X. Tian, and J.A. El-Awady: Scr. Mater., 2017 , vol. 127 , pp. $68-71$.

5. S. Sandlöbes, S. Zaefferer, I. Schestakow, S. Yi, and R. GonzalezMartinez: Acta Mater., 2011, vol. 59, pp. 429-39.

6. S. Tekumalla, S. Seetharaman, A. Almajid, and M. Gupta: Metals, 2015, vol. 5, pp. 1-39.

7. G. Liu, J. Zhang, G. Xi, R. Zuo, and S. Liu: Acta Mater., 2017, vol. 141 , pp. 1-9.
8. Z. Wu, R. Ahmad, B. Yin, S. Sandlöbes, and W.A. Curtin: Science, 2018, vol. 359, pp. 447-52.

9. J. Koike, T. Kobayashi, T. Mukai, H. Watanabe, M. Suzuki, K. Maruyama, and K. Higashi: Acta Mater., 2003, vol. 51, pp. 2055-65.

10. J.A. del Valle, F. Carreno, and O.A. Ruano: Acta Mater., 2006, vol. 54 , pp. $4247-59$.

11. R. Ma, Y. Zhao, and Y. Wang: Mater. Sci. Eng. A, 2017, vol. 691, pp. 81-87.

12. W.J. Kim, J.B. Lee, W.Y. Kim, H.T. Jeong, and H.G. Jeong: Scr. Mater., 2007, vol. 56, pp. 309-12.

13. Y. Wang and H. Choo: Acta Mater., 2014, vol. 81, pp. 83-97.

14. Q. Wang, B. Jiang, A. Tang, S. Ma, Z. Jiang, Y. Chai, B. Liu, and F. Pan: Mater. Sci. Eng. A, 2017, vol. 689, pp. 395-403.

15. B. Ham and X. Zhang: Mater. Sci. Eng. A, 2011, vol. 528, pp. 2028-33.

16. Y.Y. Lu, R. Kotoka, J.P. Ligda, B.B. Cao, S.N. Yarmolenko, B.E. Schuster, and Q. Wei: Acta Mater., 2014, vol. 63, pp. 216-31.

17. Y. Chen, N. Li, S.K. Yadav, X.Y. Liu, J.K. Baldwin, R.G Hoagland, J. Wang, and N. Mara: Microsc. Microanal., 2017, vol. 23 , pp. $754-55$.

18. W.J. Kim, S.I. Hong, Y.S. Kim, S.H. Min, H.T. Jeong, and J.D. Lee: Acta Mater., 2003, vol. 51, pp. 3293-3307.

19. J. Cížek, I. Procházka, B. Smola, I. Stulíková, R. Kužel, Z. Matěj, V. Cherkaska, R.K. Islamgaliev, and O. Kulyasova: Mater. Sci. Eng. A, 2007, vol. 462, pp. 121-26.

20. I.-C. Choi, D.-H. Lee, B. Ahn, K. Durst, M. Kawasaki, T.G. Langdon, and J.-I. Jang: Scr. Mater., 2015, vol. 94, pp. 44- 47.

21. T.H. Fang, W.L. Li, N.R. Tao, and K. Lu: Science, 2011, vol. 331, pp. $1587-90$

22. X. Wu, P. Jiang, L. Chen, F. Yuan, and Y.T. Zhu: Proc. Natl. Acad. Sci. USA, 2014, vol. 111, pp. 7197-7201.

23. H. Kitahara, T. Yada, F. Hashiguchi, M. TsUshida, and S. Ando: Surf. Coat. Technol., 2014, vol. 243, pp. 28-33.

24. M. Yang, Y. Pan, F. Yuan, Y. Zhu, and X. Wu: Mater. Res. Lett., 2016, vol. 4, pp. 145-51.

25. L. Chen, F. Yuan, P. Jiang, J. Xie, and X. Wu: Mater. Sci. Eng. A, 2017, vol. 694, pp. 98-109.

26. X.L. Wu, P. Jiang, L. Chen, J.F. Zhang, F.P. Yuan, and Y.T. Zhu: Mater. Res. Lett., 2014, vol. 2, pp. 185-91.

27. Y. Liu, B. Jin, and J. Lu: Mater. Sci. Eng. A, 2015, vol. 636, pp. 446-51.

28. X.Y. Shi, Y. Liu, D.J. Li, B. Chen, X.Q. Zeng, J. Lu, and W.J. Ding: Mater. Sci. Eng. A, 2015, vol. 630, pp. 146-54.

29. H.L. Chen, J. Yang, H. Zhou, J. Moering, Z. Yin, Y.L. Gong, and K.Y. Zhao: Metall. Mater. Trans. A, 2017, vol. 48A, pp. 3961-70.

30. P. Chui, K. Sun, C. Sun, X. Yang, and T. Shan: Appl. Surf. Sci., 2011, vol. 257, pp. 6787-91.

31. W.T. Huo, W. Zhang, J.W. Lu, and Y.S. Zhang: J. Alloys Compd., 2017, vol. 720, pp. 324-31.

32. N. Kamikawa, X. Huang, N. Tsuji, and N. Hansen: Acta Mater., 2009, vol. 57, pp. 4198-4208.

33. Z. Yin, X. Yang, X. Ma, J. Moering, J. Yang, Y. Gong, Y. Zhu, and X. Zhu: Mater. Des., 2016, vol. 105, pp. 89-95.

34. X. Liu, K. Wu, G. Wu, Y. Gao, L. Zhu, Y. Lu, and J. Lu: Scr. Mater., 2016, vol. 124, pp. 103-07.

35. F.-Y. Hung, T.-S. Lui, L.-H. Chen, and K.-J. Zhuang: Mater. Trans., 2008, vol. 49, pp. 2591-96.

36. M. Paramsothy, S.F. Hassan, N. Srikanth, and M. Gupta: $J$. Nanosci. Nanotechnol., 2010, vol. 10, pp. 956-64.

37. B. Song, G. Huang, H. Li, L. Zhang, G. Huang, and F. Pan: $J$. Alloys Compd., 2010, vol. 489, pp. 475-81.

38. X. Hu, S. Jin, H. Zhou, Z. Yin, J. Yang, Y. Gong, Y. Zhu, G. Sha, and X. Zhu: Metall. Mater. Trans. A, 2017, vol. 48A, pp. 3943-50. 